\title{
Tensiones discursivas en la escritura de Jorge Masciángioli
}

\begin{abstract}
Aldo Oscar Valesini
UNNE

Resumen

Este libro de cuentos de Jorge Masciángioli plantea de manera orgánica la relación entre mundo y lenguaje, a través de una serie de relatos en los que la lógica social (discursiva) prevalece como elemento de intercambio público en detrimento de la realidad desgarrada de los personajes.

La literatura, al modo naturalista, se introduce en los parámetros éticos, culturales, políticos de una sociedad que prioriza la apariencia, el formalismo que operan como una compensación a las carencias que no pueden cubrir.
\end{abstract}

\section{Palabras clave \\ Estética posmoderna - narrativa de Jorge Masciángioli - naturalismo y literatura}

Jorge Masciángioli publica Las moscas de Isabel en 1967 en Buenos Aires. A través de los doce cuentos que integran la colección el autor aborda distinta situaciones a través de las cuales se despliega el trasfondo de la cotidianeidad en sectores marginales, anónimos, poblado de mujeres y hombres que operan sus vidas La colección de doce cuentos organiza discursivamente una zona marginal que desarrolla un planteo acerca de los límites del estatuto del discurso literario. Detrás de una contundente lógica formal que ordena los acontecimientos comparece el sinsentido, el absurdo o la cancelación de su estatus verosímil.

El universo que comparece en los textos se alimenta en la matriz de los cuadros cotidianos, el ejercicio rutinario, el acontecer intrascendente cuya presencia es ignorada., y es precisamente esta localización la que permite descubrir los otros mundos que se yuxtaponen al conformado por la sucesión vacía de formas y gestos habituales. Sin embargo, los personajes arrastran su propio mundo como una parte de sí el hábito de lo cotidiano que en definitiva constituye el criterio para elaborar los juicios de valor. El mundo de la mujer que encuentra en las moscas el amor del que se siente privada desde la muerte de su hijo; el de la cantante de un burdel que acepta amargamente la única alternativa de soñar aquello que en definitiva no es: una bailarina de ballet, o el de Federico, el sencillo empleado de oficina que encuentra en el sexo una forma sublime de conectarse con lo superior, son fragmentos anclados en la naturaleza del ser humano y en los trasfondos psicológicos, éticos y estéticos que se entrecruzan en la configuración de los actos cotidianos.

\section{El sustrato naturalista}

El naturalismo de Émile Zola se erige como una opción estética que parte del precepto de respetar la verdad, entendida como el registro minucioso e imparcial del espectáculo que ofrece la realidad humana. Espectáculo no como escenario de contemplación, sino de intervención crítica, de interrogación acerca de los límites morales que invocan los hechos. Lo 
verdadero tiene cabida sin restricciones morales ni estéticas: cualquier temática es susceptible de tratamiento literario.

La homogeneidad discursiva de esta obra se conforma a partir del despliegue de un lenguaje rico, un estilo cuidado y una sensibilidad poética que, al tiempo que desnuda las miserias del hombre, desoculta las facetas que la sociedad burguesa ignora o disimula con pudor hipócrita. Cada situación se conforma a partir de un análisis transdiscursivo fundado en la correcta relación entre causas y consecuencias, más allá de los efectos aberrantes que desencadena. La mujer que ha convertido su vida en un desesperado intento de cuidar, proteger a las moscas, vive su pobreza en una villa, donde aquellas le proporcionan la felicidad que ya no puede esperar de un hijo muerto.

El naturalismo impone una exégesis que provoca la sensibilidad, pero al mismo tiempo desfonda las estructuras maniqueas que sostienen las apariencias.

Es reiterado el uso del narrador omnisciente, en tercera persona fuera del relato que restringe su focalización en la visión de un personaje -el protagonista- y de ese modo se introduce en la conciencia hasta lograr la "naterialización de lo indecible", en la concreción de aquellas certezas espontáneas que casi siempre se olvidan, o se desplazan desde la mirada o el pensamiento para alimentar el territorio de otras zonas indeterminadas como el amor, el espanto, el temor, la resignación. "'Es fea.' Le dolió reconocerlo, pero ¿podia, acaso, ignorar la fealdad de Ofelia, aunque fuese su hija?. Tenia el rostro redondo, la piel áspera y seca, los ojos pequeños, hundidos,..." (Masciángioli, 1967:52)

Esta imparcialidad omnisciente permite que el discurso opere suplementando la realidad, explorando aquello que se presenta a la observación pero no desde la simple mirada, sino desde los procesos de la conciencia: la mujer que en el cuento "La ropa blanca" reconoce una realidad que había negado pero que ya no tolera sostener. El ajuar que está cosiendo y bordando con esmero desde hace décadas para el casamiento de su hija que sin dudas ya no habría de usarlo nunca. Repentinamente se dice una verdad que conoce y con la que convive, aunque haya sido negada sucesivamente en bien de mantener el sueño que ella misma alimentó en la hija desde joven. Un día de fuerte viento decide dejar volar las innumerables piezas del ajuar, confeccionadas primorosamente en telas de hilo blanco, con bordados y encajes. Todos los vecinos aparecen al rato con la ropa rescatada, lamentando los daños. A su regreso, la hija comprende que no hubo ningún accidente, sino que lo ocurrido fue obra de su madre.

Ahora bien, ese discurso homogéneo asimilado al autor ¿cuál es la esfera social que se muestra? De una categoría organizada a partir de las condiciones ordenadas por la cultura en el ámbito de lo decible? La que responde a las condiciones de la discursivización a través de la lógica, el decoro o las convenciones?

La obra de Maciángioli no condice con las idealizaciones conformistas ni con la denuncia panfletaria. Simplemente opera sugestivamente en la formación social a través de indicadores que trascienden los mecanismos de la causalidad material y desnuda las enormes extensiones de los sueños, las fantasías o los deseos de los hombres y las mujeres que, desde espacios periféricos, construye su vida en una tensión que revela su inserción en una sociedad de la que son parte, aunque no los contiene completamente.

El análisis de la conciencia se comparece con la transformación del mundo: frente a lo inusitado, extravagante, a veces absurdo, producido por la decisión de los personajes, el mundo, 
en su indiferencia, su ajenidad, también se fragmenta y responde a esa otra lógica, tal vez de modo aleatorio y termina restableciendo el orden. Los vecinos que al final le traen cajas con moscas a Isabel, tras haberle dejado escapar las que ella custodiaba celosamente; los vecinos del barrio que le devuelven las prendas del ajuar echadas a volar o la misma máquina ciega de la administración, que ante el despido de Mercedes, la vulgar empleada que Federico idolatra eróticamente en la oscura cocina del piso de la oficina, le proveería seguramente otra que le proporcionaría ese mismo sostén afectivo en una ciudad ciega y anónima.

En definitiva, se está diciendo que el orden como condición de felicidad no es sino persistir, que la felicidad depende antes de la experiencia individual que de las condiciones de la historia, de la vida, o del destino.

Harry Levin:1963 sostiene en relación con la estética de Zola:

Si la novela cientifica o naturalista es el equivalente literario de la ciencia y el progreso, las técnicas pertinentes son las que ayuden a la disección del hombre al modo cientifico: estudio del determinismo hereditario y de los factores fisicos sobre los caracteres; de ahi la abundancia de datos físicos y fisiológicos en la caracterización de personajes, hasta el punto de llamársele "escuela fisiológica" por la importancia concedida a la influencia del temperamento, los nervios y otros órganos en la personalidad y la conducta (recuérdese que el positivismo concebía la psicología como una rama de la fisiología), para lo cual Zola maneja sólo las leyes naturales del postivismo, prescindiendo de toda implicación metafisica

He aquí una visible diferencia respecto de Masciángioli. Aunque el libro presenta una secuencia de situaciones que conforman el horizonte de la vida cotidiana de seres anónimos en el discurso social contemporáneo, el mundo que prevalece es el de la interioridad, de la imaginación no como cualidad que aproxima a la realidad, sino como suplemento que proporciona sentido a la vida.

\section{El sustrato semántico}

Roland Barthes (1968) insiste en la naturaleza histórica del arte definida a partir de la resistencia que impone frente a las formas dominantes en una cultura. En el mismo sentido, Pierre Bourdieu (2003) describe el campo intelectual como un sistema de fuerzas que configuran al autor en su relación con la época, pero que al mismo tiempo sostienen la autonomía del discurso respecto de las estructuras centrales.

Así entendida, la obra se ubica en una situación límite y conforma el texto de goce, según Roland Barthes. Este concepto se determina en relación con el acto comunicativo: el goce no se marca en el texto, sino que opera en el lector, que vertiginosamente es abandonado por el discurso en un entorno que desborda las respuestas provistas por la tradición y la cultura. No equivale al concepto de novedad, como lo concebían las vanguardias en relación con la forma, sino al despliegue ideológico de un nuevo espacio discursivo. 
La obra es entonces la que, colocada en el límite, desconociendo los sistemas de posibilidad que la historia provee, se constituye en un signo que revela su precaria entidad de convención.

En el cierre formal de sus textos, Jorge Masciángioli transgrede las convenciones cotidianas del sentido común en beneficio de la lógica como categoría transindividual que organiza y justifica el mundo. Esta escisión entre lo universal y lo individual es el gran tema que sostiene el libro como una apertura hacia una dispersión del centro estipulado como paradigma único. Los sistemas sociales operan entonces como socialización que controla los usos aberrantes de la razón de acuerdo con las coordenadas ideológicas y culturales de una época. ${ }^{74}$ En otros términos, la lógica necesita del ser humano como parte de la realidad y no solo del discurso.

En los textos de nuestro autor se introducen elementos formales que los asimilan a las estrategias de lo fantástico según T. Todorov (1981), aunque la retórica no suple los registros temáticos ajenos a la modalidad. ${ }^{75} \mathrm{El}$ desajuste entre el mundo narrativo y las redes inferenciales con que se lo desarrolla discursivamente se resuelve a través de constantes sostenidas en la lógica. Este procedimiento impone una cercanía celosamente cuidada y difícil de evitar con el lector, en cuanto el mundo narrativo participa de los sustratos que la tradición, la cultura y las prácticas cotidianas admiten como nuestro propio mundo. Estos personajes, protagonistas de situaciones que esencialmente cuestionan la imagen convencional del hombre como prototipo universal merced a la configuración de los seres como "naturaleza naturante" (Spinoza), encuentran en la transgresión la postulación del orden que supera los convencionalismos.

Cada cuento condensa metonímicamente un fragmento de la vida, la duplica en un proceso reconstructivo que va desde la inversión hasta la desintegración. El cuento "Los invitados" se focaliza en la señora Cecilia, quien ha pasado los últimos quince años de su vida junto a su ama de llaves repitiendo la secuencia de cocinar y poner la mesa esperando la llegada de tres invitados prestigiosos que prometieron visitarla para almorzar y que sin embargo no llegan. El día que su médico advierte que está agonizando, la empleada confunde a los atónitos empleados de la funeraria con los visitantes esperados y cuando le lleva la "buena nueva" a la dueña de casa, ésta ya ha muerto. La gentil obsesión de la dueña de casa se constituye en el eje que moviliza a su entorno, y la visita esperada termina siendo recibida por la empleada, aunque a través de una sustitución trágica. Los hechos se producen correcta y adecuadamente, aunque desarticulan el tópico instalado como marco que contiene el proceso semiótico del relato.

Iterativamente los acontecimientos de las historias son alterados por un hecho que fractura la normalidad cotidiana de la vida. Ese momento que desplaza el orden se constituye en una diferenciación discursiva, en la constatación de la asimetría entre discurso y hábito, entre la rutinaria lectura de la vida y la asunción de una autonomía reveladora del carácter convencional y arbitrario de la superficie de las cosas.

\footnotetext{
${ }^{74}$ Pensamos, por ejemplo, en Jonathan Swift en el siglo XVIII y en los postulados expuestos por Michel Foucault en Vigilar y castigar.

${ }^{75}$ Lo fantástico produce un desajuste entre el mundo narrativo y el sistema de convenciones que constituyen las pautas de entendimiento y comprensión del mundo de la comunidad. Los textos operan inversamente: muestran que nuestra vida cotidiana está plagada de rutinas, esquemas o convicciones que son fantásticas, a pesar de que no lo advertimos.
} 


\section{Conclusión}

La obra de Masciángioli opera desde la consigna naturalista en cuanto elabora una suerte de taxonomía de situaciones límite del hombre contemporáneo. La extrema fidelidad a la realidad puede parecer subversiva, agobiante, incluso absurda, pero el deber del escritor es, como el del médico, "curar los males de la sociedad". Sin embargo la indagación no se satisface con la mera descripción como lo propugnaron los escritores del siglo XIX. Particularmente la causalidad que fundamenta las situaciones proviene de la lectura psicoanalítica del sujeto. Antes que la realidad objetiva, material de los objetos predomina la realidad de la mente de los protagonistas, que en definitiva, constituye la entidad del mundo de cada uno ${ }^{76}$.

El discurso entonces organiza lógicamente lo que en sustancia contraviene la lógica: la interminable espera de quince años, el recurrente rito frente al altar de los pechos de la empleada o el diálogo nocturno de una mujer sola con una foca que aparece muerta a la mañana, indagan acerca de los espacios del ser que están al margen de la razón como instrumento social, y son válidos en relación con la praxis misma.

En todos los cuentos la figura recurrente de la catecresis funciona como núcleo que cuestiona la organización idealista de los cuadros sociales. Aquí los hechos clave intervienen para sustituir un vacío que amenaza con la negación, la catástrofe o la muerte. Cada una restituye el orden de la vida y lo sostiene como una alternativa que se afirma al margen de lo que la generalidad entiende como único patrón, ya sea moral, estético o consuetudinario.

En un horizonte conceptual caracterizado por las estrategias de lo fantástico, entendido como la configuración del mundo cotidiano planteado en términos que lo desbordan, el discurso adquiere una fuerza reveladora de una tensión entre las formas de la sociedad y la forma estética.

Este desplazamiento opera transdiscursivamente en el acto de lectura generando un reacomodamiento en el que las jerarquías morales, estéticas o sociales son resignificadas.

El lenguaje, como dispositivo retórico adquiere entonces una incidencia localizada en la generación de una crisis del sentido del mundo, que denuncia la ceguera de la sociedad como entidad anónima y amenaza con socavar las certezas que constituyen la matriz desde la cual se visualiza un exterior que a través del discurso, es también el propio.

La moral del arte no es necesariamente la moral social cuando ésta amenaza ofrecer un estereotipo que disimula, oculta o disfraza las terribles víctimas que la vida contemporánea contiene sin saberlo.

\footnotetext{
${ }^{76}$ El naturalismo es la expresión de una necesidad de objetivación, del cese de la fe en el pacto entre el individuo y la sociedad, nacida precisamente de la crisis de la concepción individualista del mundo, propia del capitalismo liberal.
} 


\section{Referencias}

BARTHES, Roland (1968), El grado cero de la escritura, Barcelona, Siglo XXI (1972), Crítica y Verdad, Buenos Aires, Siglo XXI.

BOURDIEU, Pierre (2003), Campo de poder, campo intelectual, Buenos Aires, Quadrata. FOUCAULT, Michel (1976), Vigilar y castigar, México, Siglo XXI.

LEMAITRE, Jules (1899) Contemporaines, Paris, Garnier.

LEVIN, Harry (1963), The Gates of Horn: A Study of Five French Realists, Nueva York, Oxford University Press

MASCIÁNGIOLI, Jorge (1967), Las moscas de Isabel, Buenos Aires, Centro de Editor de América Latina.

TODOROV, Tzvetan (1981), Introducción a la literatura fantástica, México, Premia editores.

Aldo Oscar Valesini es Profesor y Licenciado en Letras (UNNE), Doctor en Literatura (Universidad Católica de Valparaíso, Chile). Realizó un curso de posdoctorado en la Universidad de Murcia, España. Ha participado como expositor en numerosos encuentros y jornadas de la especialidad en el país y el extranjero. Ha publicado en revistas nacionales y extranjeras. 